\title{
CONGENITAL UNILATERAL ABSENCE OF THE VAS DEFERENS
}

Dear Editor,

I would like to share my experience of a case of congenital unilateral absence of left vas in a serving soldier who reported for vasectomy. Congenital unilateral absence of the vas deferens is a rare anomaly. Incidence is 0.06 to $1 \%$ in healthy men [1]. By itself it has little clinical significance other than an associated $79 \%$ incidence of ipsilateral renal agenesis [2]. Hunter in 1775 first described the unilateral absence of the right vas deferens with bilateral absence of the body and tail of the epididymis [3]. It is a rare cause of male infertility when it is associated with contralateral mesonephric duct abnormality [4].

A 30-years-old serving soldier, apparently healthy, reported for vasectomy. He had three children-two males and one female. On examination left side scrotal vas was not palpable while testis was normal. Right vas, testis and epididymis were normal. During operation right vas was explored under local anaesthesia by single incision in the median raphe of the scrotum. One cm segment of the right vas was resected and the two ends occluded with $2 / 0$ silk sutures. Left side vas was not found. Further exploration revealed normal testis and caput epididymis on the left side. Patient had uneventful postoperative recovery. Patient was further evaluated by USS abdomen, both kidneys were normal. Semen analysis after two months reported no dead/alive spermatozoa.

Vas deferens is the least commonly palpated during routine physical examination and is most commonly assaulted in surgery [3]. It may be absent on one or both sides, and in whole or in part, and in the latter case may fail to establish communication with the epididymis [5]. In the population of those who elect to have a vasectomy, $0.06 \%$ to $0.8 \%$ of patients have a single vas deferens [1]. Eighty percent of patients who have cystic fibrosis have bilateral anomalies or absence of the vas deferens [6].

Embyrologically vas deferens is derived from the mesonephric duct. At the $15 \mathrm{~mm}$ stage ( 7 weeks) of gestation, the ureteral bud separates from the remaining mesonephric duct, which will subsequently differentiate into the ejaculatory duct, seminal vesicles and the ampulla of the vas deferens caudally; the vas in the midpor- tion; and distal two thirds of the epididymis cranially. The penetration of the ipsilateral metanephrogenic blastema by ureteral bud induces the development of the ipsilateral kidney. While disturbance in the development of the mesonephric duct, after separation of the ureteral diverticulum may result in the absence of the vas deferens but a normal ureter and kidney as was seen in this patient.

Routine physical examination in all male patients should include bilateral palpation for the vas deferens. The technique is as follows: The testis and the epididymis are placed on gentle traction with one hand and the first and third fingers of the other ungloved hand are placed anteriorly and posteriorly on the median raphe of the scrotum above the testis and epididymis. These fingers are gently moved laterally, allowing the spermatic cord tissue pass between them. A firm, rubbery structure, the vas deferens should be detected towards the lateral aspect of the scrotal sac.

Unilateral absence of the vas deferens is a significant physical finding that may suggest absence of ipsilateral renal unit. Contralateral abnormalities in the solitary renal unit occur in a significant percentage of such patient.

\section{REFERENCES}

1. Klapporth HJ, Young ID. Vasectomy, vas ligation and vas occlusion. Urology 1973;1: 292-300.

2. Schmidt SS. Techniques and complications of elective vasectomy. Fertil Steril 1966;17:467-82.

3. Donohue RE, Fauver HE. Unilateral absence of the vas deferens $A$ useful clinical sign. JAMA 1989;261:180-2.

4. Goldstein M, Schlossberg S. Men with congenital absence of vas deferens often have seminal vesicles. Urology 1988;140:85-6.

5. Kushwaha SS, Pendse AK. Congenital bilateral absence of vas deferens-an uncommon cause of male infertility. Surg $\mathrm{J} N$ India 1996; $12: 144$.

6. Holsclaw DS. Cystic fibrosis and fertility. Br Med J 1969:3:356.

Lt Col S CHAWLA

Classified Specialsit (Surgery), 172 Military Hospital, C/o 56 APO.

\section{POST INJECTION TUBERCULAR INFECTION}

Dear Editor,

$\mathbf{T}$ This is in reference to the article "Post injection tubercular infection" [1]. I would like to mention a few other reports in the literature of tubercular abscesses occurring at the site of subcutaneous or intramuscular injections [2.3]. Most other reports are nearly limited to one or two examples hence giving an impression that the condition is scarce. In fact, there was an epidemic of inoculation in children following vaccination against Pertussis! [3].

Theoretically, the abscess can occur in either of the two ways. Firstly if the organisms are introduced at the injection site by contaminated injection material or instrument. This primary inoculation is unusually rare. Secondly, the more common pathogenesis occurs in those cases who have recently undergone primary infection and during this early stage of the disease (incubation period) a number of bacilli reach the blood stream, either directly from the initial focus or by the way of regional lymph node or thoracic duct [4]. This sporadic dissemination, also termed as Occult Haematogenous Tuberculosis, takes place for a very short time and is unlikely to continue after delayed hypersensitivity develops. Clinical manifestation during this episode is fever which lasts for a few days. The bacilli are seeded at various organs and may heal completely, may progress to active lesion or may remain quiescent containing viable bacilli to become active again during lowered body resistance. The site of infection act as an area of lowered resistance resulting into seedling and progression of the disease if conditions are appropriate.

In the mentioned patient [1], there is a strong possibility that when the patient had fever and received injections, he was in dissemination stage resulting into seedling of bacilli at the site, rather than direct inoculation as mentioned. Secondly the speed of development of abscess depends upon the tuberculin sensitivity stanus of the patient. If he were positive then he would develop a local abscess. This may come on acutely if he is strongly positive. If negarive, then as the local abscess slowly develops, the regional lympnodes also enlarge and generalised tuberculosis may also follow [2].

Thus post injection tubercular abscess should be considered whenever a chronic local abscess forms at the injection site particalarly if there has been an interval of 2-3 weeks between injection and the development of complications. Mantoux test and chest $\mathrm{X}$-rays are again mandatory in such cases.

\section{REFERENCES}

1. Harjai MM, Bajpai RK, Chaturvedi AK. Maudar KK. Deshpande GL. Post injection tubercular infection. MJAFI 1999:55:77-8.

2. Miller FJW. Tuberculosis in children. Ist edition New Delhi. BI 
Churchill Livingstone 1986:152.

3. Oka S, State M. 13 year follow-up study of an epidemic inoculation tuberculosis in children caused by vaccination against Pertussis. American Review Respiratory Diseases 1963;88:462.

4. Speen DP. Tuberculosis. In: Krugman S, Katz SI, Gershon AA \&
Wilfort CM, editors. Infectious Diseases of children. 9th ed. Missouri: Mosby 1992:551-2.

\section{Capt RP SINGH TOMAR}

MO Paediatrics, Military Hospital Golconda 500008.

\section{REPLY}

\section{Dear Editor,}

$\mathbf{T}$ The article has emphasized the rarity of primary implantation of tubercle bacilli into subcutaneous tissue, which is the main context of the article. The sporadic or occult haematogenous tuberculosis, causing the patient to be in the dissemination stage is unlikely because of absence of clinical and biochemical pointers for the same. Serial recording of ESR did not show any increase in the value. Mantoux test and $\mathrm{X}$-ray chest and $\mathrm{X}$-ray hip did not point towards an acitve progression of disease. There was no evidence detected of any other primary tubercular focus. In this case, the patient had been symptomatic for more than two and a half months with features of local abscess and persistent sinus formation and the absence of any haematological, biochemical and radiological parameters suggest the direct inoculation of site has been the most likely cause, favouring local conditions due to local clot or haematoma formation leading to tissue hypoxia. Notwithstanding, the reader has brought out a very pertinent point that a post injection tuberculosis abscess needs to be considered in the differential diagnosis provided mantoux test and X-ray examination is suggestive.

\section{Lt Col MM HARJAI}

Reader, Department of Surgery, Armed Forces Medical College, Pune 411040.

\section{MYECETOMA AND ASPERGILLOMA}

Dear Editor,

T The Radiological Quiz (MJAFI 55;2: 148,172) was very interesting. However, the use of term mycetoma for pulmonary aspergillosis is not appropriate. Mycetoma is defined as a localised lesion of cutaneous and/or subcutaneous tissue with or without involvement of bone, characterised by swelling, deformity, formation and rupture of abscess leading to draining fistulae [1,2]. Actinomycotic mycetoma are caused by members of Actinomyces, Nocardia or Streptomyces spp while Eumycotic mycetoma are the result of infection with variety of true fungi like Madurella, Acremonium, Cephalosporium, Allescheria etc, but NEVER due to Aspergillus sp [1-3].

Pulmonary diseases due to Aspergillus (infection or colonisation of preformed cavity) are collectively called as Pulmonary Aspergillosis with very wide spectrum of clinical manifestations [1,4]. Aspergillus ball (Aspergilloma) is one of them. These do not qualify to be called as mycetoma.

\section{REFERENCES}

1. Hay RJ, Mackenzie DWR. Fungal Infections (Mycoses). In: Weatherall DJ, Ledingham JGG, Warell DA, editors. Oxfords Text Book of Medicine, 3rd edn, Oxford Medical Publication 1996:797-824.

2. Dory YA. Subcutaneous Mycoses. In: Doory YA, editor. Laboratory Medical Mycology. Philadelphia, Lea \& Febinger 1980:197-203.

3. Doory YA. Subcutaneous Mycoses. In: Doory YA, editor. Laboratory Medical Mycology. Philadelphia, Lea \& Febiger 1980:208-18.

4. Cotran RS, Kumar V, Robbins SL. Fungal, Protozoal and Helminthic Diseases and Sarcoidosis. In: Cotran RS, Kumar V, Robbins SL, editors. Robbins Pathologic Basis of Disease. Philadelpia, WB Saunders Company 1989;385-433.

Lt Col S GOKHALE ", Lt Col JJJ FALLEIRO sM ${ }^{+}$.

Classified Specialist (Path and Micro), ${ }^{+}$Classified Specialist (Pathology), Military Hospital, Bareilly 243001, UP.

\section{REPLY}

I am grateful to both the readers for having read the article and their views as expressed in most pathology books.

"Any chronic pulmonary cavity colonized by fungus and when the fungal hyphae forms a ball or mycetoma which lies free in the cavity" quotes a standard Textbook of Imaging [1].

A mycetoma (fungal ball) is a matted collection of fungal hyphae, cellular debris, fibrin and mucous. The fungus may be an aspergillus, candida, norcadia, phycomycetes or tricophyton [2]. However majority of mycetomas are caused by aspergillus to the extent that the term aspergilloma is often used synonymously.

In this case the infecting fungus was not known so mentioning of term mycetoma was not very inappropriate however chronic pulmonary cavities are most commonly infected by species of Aspergillus fumigatus or niger [3] and are referred as pulmonary aspergillosis with wide spectrum of clinical manifestation, aspergillus ball (Aspergilloma) is one of them.

\section{REFERENCES}

1. Sutton D. Fungal infections in Textbook of Radiology and Imaging, 6th edition. Edinburg, Churchill Livingstone 1998;1:437-40.

2. Roberts $\mathrm{CM}$, Citron $\mathrm{KM}$, Strickland $\mathrm{B}$. Intratoracic aspergilloma, Role of CT in diagnosis and treatment. Radiology 1987;65:123-8.

3. Kline D, Gamsu G. Thoracic manifestations of aspergilloma. AJR 1980;124:543-52.

Col HARIQBAL SINGH ${ }^{*}$, Maj Gen RK JETLEY vSM ${ }^{+}$.

* Senior Adviser(Radiology), Command Hospital (SC), Pune 411 $040,{ }^{+}$DDMS, Northern Command, C/o 56 APO. 